\title{
New Cardiovascular Biomarkers in Ischemic Heart Disease-GDF-15, A Probable Predictor for Ejection Fraction
}

\author{
Daniel Dalos ${ }^{1} \mathbb{D}$, Georg Spinka ${ }^{1}$, Matthias Schneider ${ }^{1}$, Bernhard Wernly ${ }^{2}$, Vera Paar ${ }^{2}$, \\ Uta Hoppe $^{2}$, Brigitte Litschauer ${ }^{3}$, Jeanette Strametz-Juranek ${ }^{1}$ and Michael Sponder ${ }^{1, *}$ \\ 1 Division of Cardiology, Medical University of Vienna, 1090 Vienna, Austria \\ 2 Division of Cardiology, Paracelsus Medical University of Salzburg, 5020 Salzburg, Austria \\ 3 Department of Pharmacology, Medical University of Vienna, 1090 Vienna, Austria \\ * Correspondence: michael.sponder@meduniwien.ac.at; Tel.: +43-1-40-400-46140; Fax: +43-1-40-400-42160
}

Received: 12 June 2019; Accepted: 24 June 2019; Published: 27 June 2019

check for updates

\begin{abstract}
Background: Various biomarkers have been associated with coronary artery disease (CAD) and ischemic heart failure. The aim of this study was to investigate the correlation of serum levels of soluble urokinase-type plasminogen activator receptor (suPAR), growth differentiation factor 15 (GDF-15), heart-type fatty acid-binding protein (H-FABP), and soluble suppression of tumorigenicity 2 (sST2) with left ventricular ejection fraction (EF) in CAD patients and controls. Methods and Results: CAD patients were divided into three groups according to their EF as measured by the biplane Simpson method (53-84\%, 31-52\%, $\leq 30 \%)$. Overall, 361 subjects were analyzed. In total, 155 CAD patients had an EF of $53-84 \%, 71$ patients had an EF of $31-52 \%$, and 23 patients had an EF of $\leq 30 \%$ as compared to 112 healthy controls (age $51.3 \pm 9.0$ years, $44.6 \%$ female). Mean ages according to EF were $62.1 \pm 10.9,65.2 \pm 10.1$, and $66.6 \pm 8.2$ years, respectively, with females representing 29.0, 29.6, and 13.0\%. suPAR, GDF-15, H-FABP, and sST2 values were significantly higher in CAD patients and showed an exponential increase with decreasing EF. In a multiple logistic regression model, GDF-15 ( $p=0.009)$, and NT-brain natriuretic peptide $(p=0.003)$ were independently associated with EF. Conclusion: Biomarkers such as suPAR, GDF-15, H-FABP, and sST2 are increased in CAD patients, especially in highly impaired EF. Besides NT-proBNP as a well-known marker for risk prediction, GDF-15 may be an additional tool for diagnosis and clinical follow-up.
\end{abstract}

Keywords: heart failure; ejection fraction; soluble urokinase-type plasminogen activator receptor (suPAR); growth differentiation factor 15 (GDF-15); heart-type fatty acid-binding protein (H-FABP); soluble suppression of tumorigenicity 2 (sST2)

\section{Introduction}

Coronary artery disease (CAD) resulting in chronic heart failure (CHF) is still one of the most important topics in socio-economic fields despite various advancements in treatment options over the last decades.

Several pathophysiological processes such as inflammation or myocardial stress have to be considered to understand the complexity of CAD and the ventricular remodeling mechanisms leading to CHF. During the last years, cardiovascular biomarkers reflecting these sequences have raised the attention of many research groups in order to identify patients at risk at an early timepoint, as well as to optimize their treatment strategies.

Elevated levels of soluble urokinase-type plasminogen activator receptor (suPAR), a membrane-bound receptor, have been associated with coronary calcification [1], systemic inflammation [2], and CHF [3]. 
Growth differentiation factor 15 (GDF-15) is a transforming growth-factor beta cytokine that is mainly expressed in inflammatory settings [4,5], and its prognostic utility has been previously described in cardiovascular disease [6], especially in CHF [7].

Heart-type fatty acid-binding protein (H-FABP) represents a protein in cardiomyocyte cytoplasm and can be found in skeletal muscle [8], cardiac microvasculature, and endothelial cells as well [9]. $\mathrm{H}$-FABP in cardiomyocytes is indispensable to ensure a high flux of long-chain fatty acids and therefore plays an important role in the energy supply.

Suppression of tumorigenicity (ST) 2 is an interleukin (IL)-1 receptor, which can occur as transmembrane receptor and a soluble form (sST2). The natural ligand of ST2 is IL-33, which acts as a traditional cytokine and as a transcription factor [10] binding to circulating sST2. Soluble ST2 serves as a decoy receptor inhibiting the IL-33/ST2-ligand (ST2L) complex resulting in an attenuation of IL-33-mediated inflammation [11], and consequently limits the cardioprotective effect of IL-33/ST2L activation. Increased levels of sST2 have been described in acute coronary syndromes [12], CHF [13], chronic obstructive pulmonary disease, and sepsis [14].

Although there is quite a wide range of studies depicting the impact of aforesaid biomarkers on poor clinical outcome in CHF [7,15-20], their detailed course of plasma levels in decreasing left ventricular ejection fraction (EF) has not yet been investigated. The aim of this analysis was to determine suPAR, GDF-15, H-FABP, and sST2 levels in CHF patients and, furthermore, to investigate their association with $\mathrm{EF}$ in comparison to the well-established biomarker N-terminal pro brain natriuretic peptide (NT-proBNP).

\section{Methods}

The clinical trials registration number was NCT02097199 (IPHAAB-study)/NCT02159235, under the title "Heavy Metals, Angiogenesis Factors and Osteopontin in Coronary Artery Disease".

\subsection{Subjects and Patient Population}

Between October 2011 and December 2017, 249 patients with recently angiographically proven CAD were recruited in course of their inpatient stay at the Medical University of Vienna, Austria, in the Department of Internal Medicine II/Cardiology. Patients were included if coronary angiography revealed any atherosclerotic alteration in at least one coronary artery, regardless of any criteria necessitating coronary intervention. Patients were also included if any coronary intervention had been performed $\leq 7$ days prior to enrolment. This cohort was further subdivided into three subgroups depending on left ventricular ejection fraction (EF): (1) $53-84 \%$, (2) $31-52 \%$, and (3) $\leq 30 \%$. This classification was done in adherence to the current recommendations of the American Society of Echocardiography and the European Association of Cardiovascular Imaging [21] without any gender-specific analysis.

As a control group (to obtain reference values for the mentioned biomarkers) we recruited 112 subjects without angiographically proven CAD. In this group we performed a bicycle stress test (Ergometer eBike comfort, GE Medical Systems, Freiburg, Germany). Only subjects without corresponding anamnesis, typical symptoms, and/or ischemia-related ECG-abnormalities at rest or exhaustion were included in the control group.

In both groups detailed anthropometric and anamnestic data as well as routine laboratory parameters were assessed.

The study was carried out in adherence to the Declaration of Helsinki and its later amendments. The protocol has been approved by the Ethics Committee of the Medical University of Vienna and informed consent was obtained from all participating subjects prior to any study-related procedure.

\subsection{Echocardiographic Analysis}

Echocardiographic data was obtained with the use of the commercially available ultrasound systems (GE Medical Systems Vivid 7 Dimensions, Horton, Norway). All measurements were 
performed by experienced board-certified physicians according to the recommendations of the American Society of Echocardiography and the European Association of Cardiovascular Imaging [21]. The examiners were blinded to the levels of suPAR, GDF-15, H-FABP, and sST2. EF was calculated using the biplane method of disks with the following formula: (end-diastolic volume minus end-systolic volume) divided by end-diastolic volume (biplane Simpson method).

\subsection{Laboratory Analysis}

Blood samples were taken from an arm vein after 10 minutes in a lying position with a tube/adapter system. Samples were then placed in a standard centrifuge (Rotanta 460, Hettich GmbH \& Co. KG, Tuttlingen, Germany) and were processed with $2500 \mathrm{rpm}$ for $10 \mathrm{~min}$.

Serum levels of suPAR, GDF-15, H-FABP, and sST2 were analyzed by utilizing enzyme-linked immunosorbent assay (ELISA) kits that are commercially available (Duoset DY206, DY1678, DY807, DY957; R\&D Systems, Minneapolis, MN, USA). Preparation of all necessary reagents and measurements were performed according to the instructions supplied by the manufacturer. In short, patient serum samples and standard protein were added to the wells of the ELISA plates (Nunc MaxiSorp flat-bottom 96-well plates, VWR International GmbH, Vienna, Austria) and were incubated for two hours. ELISA plates were then washed using a Tween 20/PBS solution (Sigma Aldrich, St. Louis, MO, USA). In the next step, a biotin-labelled antibody was added and plates were incubated for another two hours. Plates were then washed once more and a streptavidin-horseradish-peroxidase solution was added to the wells. By adding tetramethylbenzidine (TMB; Sigma Aldrich, St. Louis, MO, USA) a color reaction was generated. Optical density (OD) values were measured at $450 \mathrm{~nm}$ on an ELISA plate-reader (iMark Microplate Absorbance Reader, Bio-Rad Laboratories, Vienna, Austria).

The analysis was performed according to the manufacturer's instructions. The coefficients of variation (CV) were for suPAR: $2.1-2.7 \%$ (intra-assay) and 5.1-5.9\% (inter-assay); for H-FABP: $0.3-4.7 \%$ (intra-assay) and 1.3-17.4\% (inter-assay); for sST2: 4.4-5.6\% (intra-assay) and 5.4-7.1\% (inter-assay); and for GDF-15: $4.7-5.9 \%$ (intra-assay) and 1.8-2.8\% (inter-assay).

\subsection{Statistical Analysis}

Statistical analysis was done with SPSS 20.0 (IBM, Armonk, NY, USA). Dichotomous variables are expressed as frequencies or percentages. Continuous and normally distributed data is described by means \pm standard deviation (SD), not normally distributed data as median/25th quartile/75th quartile. Comparisons between groups were made using the Chi-square or Fisher's exact test for categorical variables, and the Student $t$-test or Mann-Whitney $\mathrm{U}$ test for continuous variables, as appropriate. Correlations between continuous parameters were calculated using the Spearman coefficient.

The influence of relevant parameters on EF was investigated first by univariate logistic regression. To identify the most relevant predictors a multiple regression model was selected from the scope of variables that reached statistical significance in univariate analysis by a backward procedure. The significance limit for a predictor to enter the model was 0.05 . All tests were two-sided and $p$-values $\leq 0.05$ were considered significant.

\section{Results}

\subsection{Baseline Characteristics}

Out of 249 CAD patients, 155 had an EF of $53-84 \%$, 71 had $31-52 \%$, and 23 patients had a severely impaired EF $(\leq 30 \%)$. Patients were $62.1 \pm 10.9,65.2 \pm 10.1$ and $66.6 \pm 8.2$ years old, and were female in $29.0 \%, 29.6 \%$, and $13.0 \%$ of cases, respectively. The control group consisted of 112 healthy adults with a mean age of $51.3 \pm 9.0$ years and with a higher proportion of women (44.6\%). The detailed baseline characteristics concerning cardiovascular risk factors and routine laboratory assessment according to the four different groups are depicted in Table 1. 
Table 1. Baseline characteristics.

\begin{tabular}{|c|c|c|c|c|c|}
\hline & $\begin{array}{c}\text { Control } \\
(n=112)\end{array}$ & $\begin{array}{c}\text { EF } 53-84 \% \\
(n=155)\end{array}$ & $\begin{array}{c}\text { EF } 31-52 \% \\
(n=71)\end{array}$ & $\begin{aligned} \mathrm{EF} & \leq 30 \% \\
(n & =23)\end{aligned}$ & $p$-Value \\
\hline Age (years) & $51.3 \pm 9.0$ & $62.1 \pm 10.9$ & $65.2 \pm 10.1$ & $66.6 \pm 8.2$ & $<0.001$ \\
\hline Female sex (\%) & 44.6 & 29.0 & 29.6 & 13.0 & 0.006 \\
\hline Hypertension (\%) & 38.4 & 92.9 & 93.0 & 95.7 & $<0.001$ \\
\hline Family history of CAD (\%) & 42.0 & 59.4 & 56.3 & 52.2 & 0.040 \\
\hline Diabetes (\%) & 5.4 & 21.9 & 25.2 & 34.8 & $<0.001$ \\
\hline Dyslipidemia (\%) & 34.8 & 92.3 & 91.5 & 73.9 & $<0.001$ \\
\hline BMI $\left(\mathrm{kg} / \mathrm{m}^{2}\right)$ & $27.4 \pm 4.2$ & $27.8 \pm 4.8$ & $28.6 \pm 5.7$ & $29.5 \pm 6.4$ & 0.226 \\
\hline $\mathrm{SBP}(\mathrm{mmHg})$ & $138 \pm 16$ & $131 \pm 16$ & $128 \pm 16$ & $129 \pm 19$ & 0.004 \\
\hline $\mathrm{DBP}(\mathrm{mmHg})$ & $84 \pm 12$ & $76 \pm 10$ & $74 \pm 10$ & $79 \pm 17$ & $<0.001$ \\
\hline HR (bpm) & $67 \pm 9$ & $68 \pm 12$ & $71 \pm 15$ & $77 \pm 13$ & 0.003 \\
\hline Cholesterol (mg/dL) & $200 \pm 40$ & $180 \pm 52$ & $164 \pm 41$ & $163 \pm 56$ & $<0.001$ \\
\hline Triglycerides (mg/dL) & $129 \pm 78$ & $153 \pm 88$ & $149 \pm 83$ & $148 \pm 72$ & 0.605 \\
\hline LDL $(\mathrm{mg} / \mathrm{dL})$ & $117 \pm 35$ & $107 \pm 40$ & $94 \pm 41$ & $96 \pm 35$ & 0.495 \\
\hline HDL (mg/dL) & $58 \pm 18$ & $48 \pm 14$ & $43 \pm 12$ & $37 \pm 10$ & 0.005 \\
\hline Creatinine (mg/dL) & $0.9 \pm 0.2$ & $1.1 \pm 0.8$ & $1.2 \pm 0.4$ & $1.4 \pm 0.5$ & 0.003 \\
\hline ASAT (U/L) & $26 \pm 13$ & $52 \pm 61$ & $52 \pm 78$ & $35 \pm 25$ & 0.311 \\
\hline ALAT (U/L) & $27 \pm 15$ & $37 \pm 27$ & $43 \pm 12$ & $31 \pm 25$ & 0.569 \\
\hline Gamma GT (U/L) & $30 \pm 40$ & $56 \pm 100$ & $89 \pm 133$ & $78 \pm 88$ & 0.076 \\
\hline $\mathrm{HbA}_{1} \mathrm{c}(\mathrm{rel} \%)$ & $5.4 \pm 0.6$ & $6.0 \pm 0.9$ & $6.6 \pm 1.7$ & $7.1 \pm 2.4$ & $<0.001$ \\
\hline Erythrocytes (T/L) & $4.7 \pm 0.5$ & $4.5 \pm 0.6$ & $4.4 \pm 0.6$ & $4.6 \pm 0.7$ & 0.028 \\
\hline Hemoglobin $(\mathrm{g} / \mathrm{dL})$ & $13.8 \pm 1.4$ & $13.3 \pm 1.8$ & $12.8 \pm 1.8$ & $12.8 \pm 2.4$ & 0.012 \\
\hline Hematocrit (\%) & $40 \pm 3$ & $39 \pm 5$ & $39 \pm 5$ & $39 \pm 7$ & 0.392 \\
\hline Platelet count (G/L) & $243 \pm 56$ & $236 \pm 74$ & $250 \pm 101$ & $217 \pm 89$ & 0.040 \\
\hline Leukocytes (G/L) & $6.6 \pm 1.7$ & $12.7 \pm 2.0$ & $8.0 \pm 2.5$ & $7.2 \pm 2.1$ & 0.494 \\
\hline
\end{tabular}

Continuous variables are shown as mean \pm standard deviation; ALAT: alanine aminotransferase; ASAT: aspartate aminotransferase; BMI: body mass index; CAD: coronary artery disease; DBP: diastolic blood pressure; EF: ejection fraction; GT: glutamyltransferase; HDL: high-density lipoprotein; HR: heart rate; LDL: low-density lipoprotein; SBP: systolic blood pressure.

\subsection{Biomarkers}

Every investigated biomarker showed a constant increase with decreasing EF. suPAR levels from controls were $1852 \pm 759 \mathrm{pg} / \mathrm{mL}$ compared to $3181 \pm 1387$ in the worst EF group $(p<0.001)$. There was a slight trend between the control cohort and CAD patients with normal EF $(1852 \pm 759$ vs. $2178 \pm 1108$ $\mathrm{pg} / \mathrm{mL}, p=0.087)$, whereas there was a steep increase between normal EF and EF 31-52\% $(2178 \pm 1108$ vs. $2851 \pm 1260 \mathrm{pg} / \mathrm{mL}, p<0.001$ ) (Figure 1).

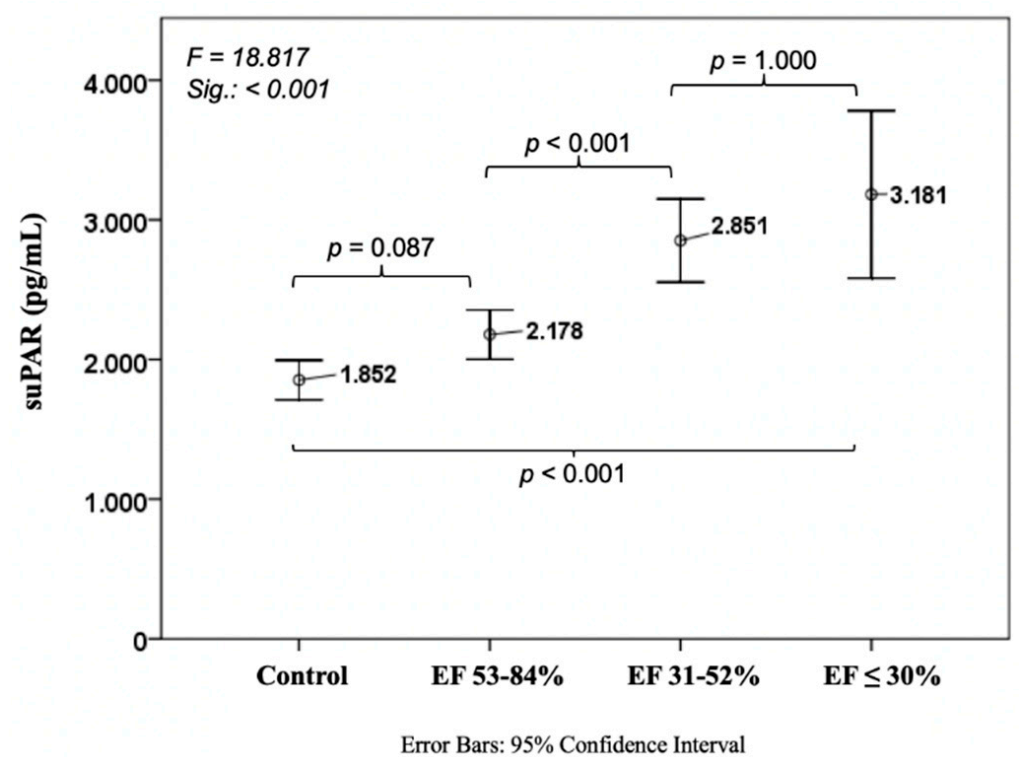

Figure 1. Course of soluble urokinase-type plasminogen activator receptor in ischemic heart disease. EF: ejection fraction; suPAR: soluble urokinase-type plasminogen activator receptor; EF: ejection fraction. 
Levels of GDF-15 were $699 \pm 554 \mathrm{pg} / \mathrm{mL}$ in the control cohort with a significant difference to the group with $\mathrm{EF} \leq 30 \%(3173 \pm 3008, p<0.001)$. We also observed a relevant distinction between controls and normal EF patients $(1500 \pm 1337, p<0.001)$ and a slight trend between normal and mid-range EF $(1975 \pm 1405, p=0.086)$ (Figure 2).

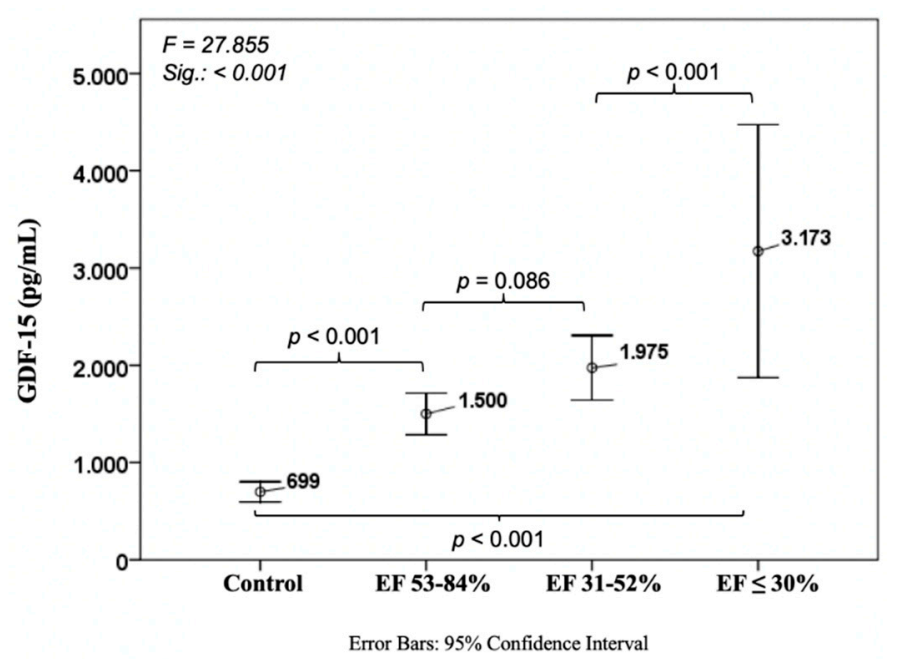

Figure 2. Course of growth differentiation factor 15 in ischemic heart disease. GDF-15: Growth differentiation factor 15 .

Such as suPAR and GDF-15, H-FABP showed an increase with decreasing EF, but in contrast to the mentioned markers, this difference did neither show significant differences between controls $2.54 \pm 4.16$ $\mathrm{ng} / \mathrm{mL}$ and $\mathrm{EF} \leq 30 \%(5.92 \pm 4.48 \mathrm{ng} / \mathrm{mL}, p=0.114)$, nor in between the three EF groups (Figure 3).

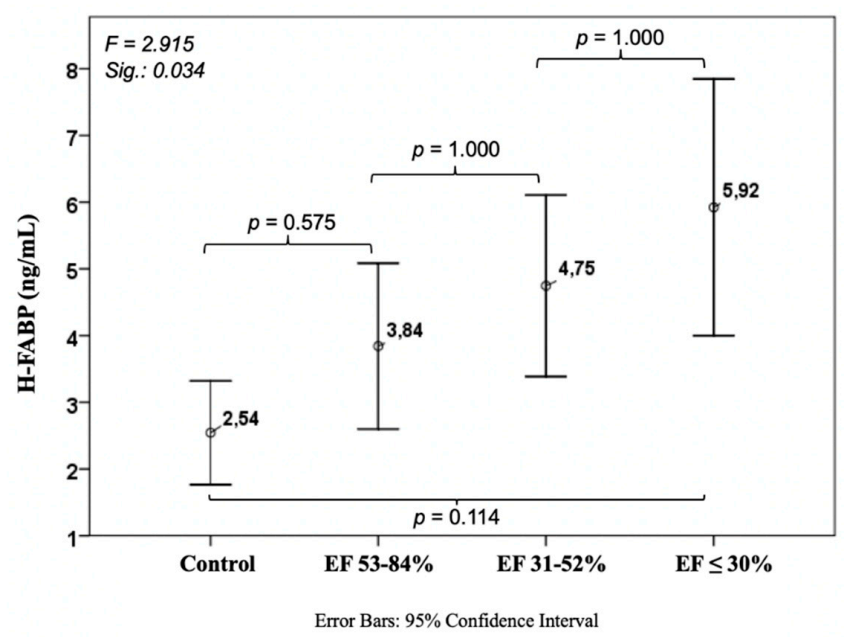

Figure 3. Course of heart-type fatty acid-binding protein in ischemic heart disease. H-FABP: heart-type fatty acid-binding protein.

Soluble ST2 levels were $6476 \pm 2916 \mathrm{pg} / \mathrm{mL}$ in patients without CAD and CHF with a considerable increase compared to the worst CHF patients $(9632 \pm 6346 \mathrm{pg} / \mathrm{mL}, p=0.038)$. No differences were observed amongst the other cohorts (Figure 4).

Concerning the well-established NT-proBNP we found the expected values of $58 \pm 103 \mathrm{ng} / \mathrm{L}$ in controls, with a significant rise in CHF patients with poor EF $(7041 \pm 8791 \mathrm{ng} / \mathrm{L}, p<0.001)$. There was a trend between the control cohort and CAD patients with normal EF $(1239 \pm 3298 \mathrm{ng} / \mathrm{L}, p=0.077)$, whereas there was a significant increase between normal and mid-range EF patients $(2843 \pm 4306 \mathrm{ng} / \mathrm{L}$, $p=0.017)$ as well as between mid-range and poor EF $(p<0.001)$ (Figure 5). 


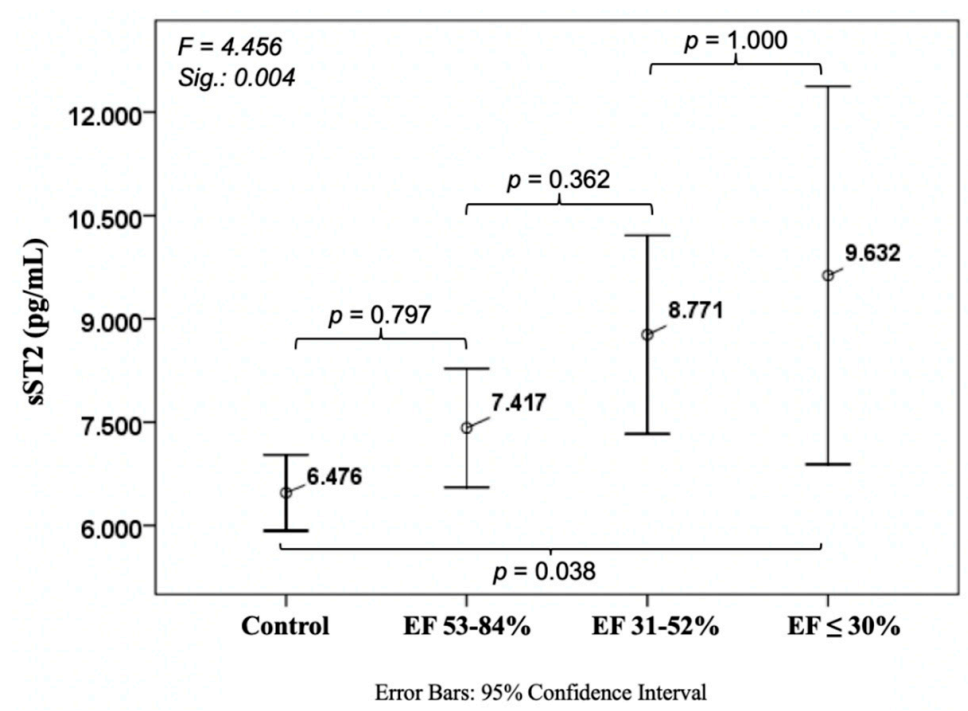

Figure 4. Course of soluble suppression of tumorigenicity 2 (sST2) in ischemic heart disease.

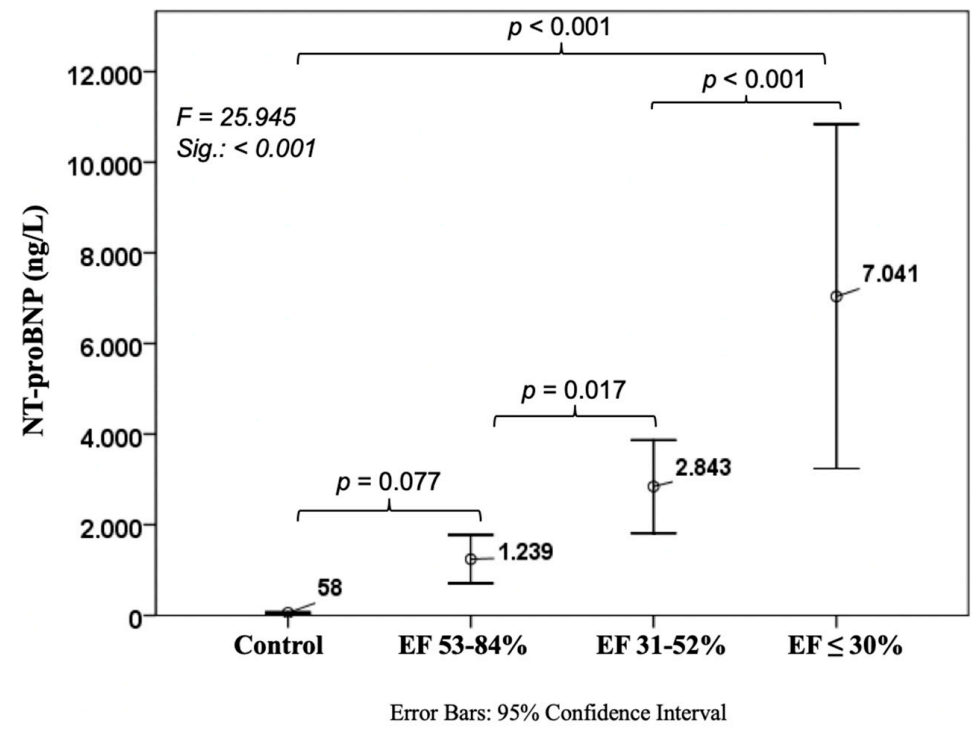

Figure 5. Course of N-terminal pro brain natriuretic peptide in ischemic heart disease. NT-proBNP: N-terminal pro brain natriuretic peptide.

In a multiple, backward logistic regression analysis, positive predictors for EF were age $(p<0.001)$, sex $(p<0.001)$, body mass index $(p=0.010), \operatorname{GDF}-15(p=0.009)$ and NT-proBNP $(p=0.003$, Table 2$)$.

Table 2. Multiple logistic regression analysis for ejection fraction.

\begin{tabular}{cccccc}
\hline Parameters & $\begin{array}{c}\text { Regression } \\
\text { Coefficient B }\end{array}$ & Standard Error & Beta & T & $p$-Value \\
\hline Constant & -2.056 & 0.334 & & -6.149 & $<0.001$ \\
Age (years) & 0.029 & 0.004 & 0.379 & 7888 & $<0.001$ \\
Sex & 0.351 & 0.083 & 0.188 & 2.614 & $<0.001$ \\
BMI $\left(\mathbf{k g} / \mathbf{m}^{2}\right)$ & 0.020 & 0.008 & 0.115 & 2.584 & 0.010 \\
GDF-15 $(\mathbf{p g} / \mathbf{m L})$ & $9.177 \times 10^{-5}$ & 0.001 & 0.158 & 2.614 & 0.009 \\
NT-proBNP $(\mathbf{p g} / \mathbf{m L})$ & $3.702 \times 10^{-5}$ & 0.001 & 0.172 & 2.983 & 0.003 \\
$F=38.0 ; p<0.001 ; r_{\text {adj }}^{2}: 0.346$ & & & & &
\end{tabular}

BMI: body mass index; GDF-15: growth differentiation factor 15; NT-proBNP: N-terminal pro brain natriuretic peptide. 


\section{Discussion}

In this analysis, we were able to confirm the diagnostic power of the biomarkers suPAR, GDF-15, H-FABP, sST2, and NT-proBNP in CHF patients compared to healthy adults. In addition, to the best of our knowledge, this is the first study to describe the detailed course of these biomarkers by means of left ventricular EF. Furthermore, we were able to show a significant association of GDF-15 with EF besides the well-established NT-proBNP in this specific patient population.

Circulating H-FABP levels increase during myocardial ischemia caused by pathological events, such as myocardial infarction, by leaking into the extracellular space [22]. However, in some cases myocardial damage due to acute physical activity might also increase its levels but they return to baseline within a few hours [23] and long-term physical training has been shown to lead to a significant decrease in H-FABP levels [24]. It can be assumed that high H-FABP levels in patients with low EF might be a sign of chronically impaired myocardial perfusion resulting in myocardial damage.

One could speculate that an increase in SST2 serum levels might be due to the chronic inflammatory state as it has been previously described in CHF patients [25]. As sST2 acts as a decoy receptor for IL-33, an upregulation might buffer an exuberant inflammation response.

Similar to SST2, suPAR (the soluble form of uPAR which is measurable after cleavage and release of membrane-bound uPAR) is involved in inflammation processes caused by numerous diseases, inter alia coronary calcification [1] and heart failure [3], and has been identified as marker for an unfavorable clinical outcome including mortality [26]. In our cohort we were able to confirm these findings as we found increasing suPAR levels dependent on the severity of CHF.

Interestingly, we observed an upregulation of GDF-15 with worsening EF as well as their independent association, together with NT-proBNP. GDF-15 is mainly secreted as a response to inflammation and hypoxemia. Due to the interaction with p53, it is released in sporadic severe stress situations, but also responds to low-level stressors during daily life activities $[27,28]$. These changes are reflected by circulating levels of GDF-15 that have been assigned protective effects regarding cell apoptosis [29] and myocardial hypertrophy [30,31].

While GDF-15 is expressed in visceral and subcutaneous adipose tissue in obese patients [32], it may also be released in atherosclerotic plaques in coronary arteries [33], in the myocardium in the course of acute cellular damages [5], as well as in peripheral tissue [34]. Due to its induction in different clinical scenarios, the use of GDF-15 as a diagnostic marker in acute cardiovascular care settings (e.g., chest pain, dyspnea) is limited.

In CAD, levels of GDF-15 are independently correlated with age, diabetes, high-sensitive C-reactive protein (hs-CRP), and natriuretic peptides in the AtheroGene study [35], which is in line with our finding of a significant correlation between GDF-15 and NT-proBNP in our CAD cohort $(r=0.727, p<$ 0.001). Furthermore, in the AtheroGene study, where 1352 patients with stable CAD were investigated, GDF-15 levels were independently associated with cardiac mortality. Schopfer et al. were able to depict the prognostic importance of GDF-15 concerning all-cause mortality in the Heart and Soul Study with 984 patients [36]. Circulating GDF-15 remains relatively stable after acute coronary syndromes without signs of HF, compared to other biomarkers such as cardiac troponin or hs-CRP showing a curve-shaped course $[37,38]$, suggesting that GDF-15 reflects chronic disease burden.

In CHF with reduced EF, GDF-15 concentrations are elevated and their constant increase in relation to HF severity, as reflected by New York Heart Association functional class and NT-proBNP, has already been described $[7,39]$. This can be confirmed by our analysis with the additional input of a better characterized cohort by means of EF. Recently, the group of Li et al. investigated fewer patients with a much smaller control cohort than in our study and found similar results. The combination of GDF-15 and NT-proBNP significantly improved the accuracy of diagnosing HF [18]. Remarkably, circulating GDF-15 is also increased in HF patients with preserved ejection fraction (HFpEF) which is in line with the theory of Paulus and Tschöpe regarding a continuous inflammatory state as the central pathomechanism in HFpEF [40,41]. 
In severely impaired CHF patients that underwent implantation of left ventricular assist devices, the mechanical support has led to a significant decrease of measurable GDF-15, showing the reversibility of even highly increased levels [42]. How this reduction may affect the protective effects of GDF-15 remains a matter of debate, especially concerning potential therapeutic interventions targeting GDF-15 with unknown effects on clinical outcome.

In summary, elevated values of GDF-15 need to be interpreted with respect to other comorbidities, clinical symptoms and laboratory values. Likewise, with NT-proBNP values that may be adulterated by renal insufficiency or significant valvular disease, GDF-15 has to be evaluated simultaneously with other inflammatory parameters in order to rule out significant infections or even septic conditions.

\section{Conclusions}

Levels of the cardiovascular biomarkers suPAR, GDF-15, H-FABP, and sST2 constantly increase when left ventricular EF decreases in CHF patients, which is comparable to the course of the well-established NT-proBNP. However, only GDF-15 is significantly associated with EF in a multivariate model and therefore may expand the spectrum of biomarkers in identifying these patients without further needs of cost-intensive diagnostic modalities.

\section{Limitations}

Due to the single-center design of this study, a center-specific bias cannot be excluded and due to a small proportion of female patients we could not perform a sex-specific analysis. Additionally, unknown or un-controlled circumstances might have influenced the investigated parameters. Finally, although alterations in GDF-15 were shown in Caucasian and Asian tumor patients [43], there is little evidence regarding racial diversification in CAD and HF [44]. Our analysis was performed in Caucasian patients only; therefore, the results have to be interpreted cautiously with regard to other ethnicities.

Author Contributions: D.D.: recruitment, manuscript preparation, statistical analysis; M.S.: echocardiographic analysis, manuscript preparation; G.S.: echocardiographic analysis; B.W.: laboratory analysis; V.P.: laboratory analysis; U.H.: manuscript preparation; B.L.: statistical analysis; J.S.-J.: study design, manuscript preparation; M.S.: study design, recruitment, manuscript preparation, statistical analysis.

Funding: This study was funded by means of the Medical University of Vienna, Austria and the Paracelsus Medical University of Salzburg, Austria.

Acknowledgments: The authors would like to thank Markus Vertesich for his technical support.

Conflicts of Interest: The authors declare no conflict of interest.

\section{References}

1. Sorensen, M.H.; Gerke, O.; Eugen-Olsen, J.; Munkholm, H.; Lambrechtsen, J.; Sand, N.P.; Mickley, H.; Rasmussen, L.M.; Olsen, M.H.; Diederichsen, A. Soluble urokinase plasminogen activator receptor is in contrast to high-sensitive C-reactive-protein associated with coronary artery calcifications in healthy middle-aged subjects. Atherosclerosis 2014, 237, 60-66. [CrossRef] [PubMed]

2. Lyngbaek, S.; Marott, J.L.; Sehestedt, T.; Hansen, T.W.; Olsen, M.H.; Andersen, O.; Linneberg, A.; Haugaard, S.B.; Eugen-Olsen, J.; Hansen, P.R.; et al. Cardiovascular risk prediction in the general population with use of suPAR, CRP, and Framingham Risk Score. Int. J. Cardiol. 2013, 167, 2904-2911. [CrossRef] [PubMed]

3. Borne, Y.; Persson, M.; Melander, O.; Smith, J.G.; Engstrom, G. Increased plasma level of soluble urokinase plasminogen activator receptor is associated with incidence of heart failure but not atrial fibrillation. Eur. J. Heart Fail. 2014, 16, 377-383. [CrossRef] [PubMed]

4. Bootcov, M.R.; Bauskin, A.R.; Valenzuela, S.M.; Moore, A.G.; Bansal, M.; He, X.Y.; Zhang, H.P.; Donnellan, M.; Mahler, S.; Pryor, K.; et al. MIC-1, a novel macrophage inhibitory cytokine, is a divergent member of the TGF-beta superfamily. Proc. Natl. Acad. Sci. USA 1997, 94, 11514-11519. [CrossRef] [PubMed] 
5. Kempf, T.; Eden, M.; Strelau, J.; Naguib, M.; Willenbockel, C.; Tongers, J.; Heineke, J.; Kotlarz, D.; Xu, J.; Molkentin, J.D.; et al. The transforming growth factor-beta superfamily member growth-differentiation factor-15 protects the heart from ischemia/reperfusion injury. Circ. Res. 2006, 98, 351-360. [CrossRef] [PubMed]

6. Wollert, K.C.; Kempf, T.; Wallentin, L. Growth differentiation factor 15 as a biomarker in cardiovascular disease. Clin. Chem. 2017, 63, 140-151. [CrossRef]

7. Kempf, T.; von Haehling, S.; Peter, T.; Allhoff, T.; Cicoira, M.; Doehner, W.; Ponikowski, P.; Filippatos, G.S.; Rozentryt, P.; Drexler, H.; et al. Prognostic utility of growth differentiation factor-15 in patients with chronic heart failure. J. Am. Coll. Cardiol. 2007, 50, 1054-1060. [CrossRef]

8. Zschiesche, W.; Kleine, A.H.; Spitzer, E.; Veerkamp, J.H.; Glatz, J.F. Histochemical localization of heart-type fatty-acid binding protein in human and murine tissues. Histochem. Cell Biol. 1995, 103, 147-156. [CrossRef]

9. Bathia, D.P.; Carless, D.R.; Viswanathan, K.; Hall, A.S.; Barth, J.H. Serum 99th centile values for two heart-type fatty acid binding protein assays. Ann. Clin. Biochem. 2009, 46, 464-467. [CrossRef]

10. Martin, N.T.; Martin, M.U. Interleukin 33 is a guardian of barriers and a local alarmin. Nat. Immunol. 2016, 17, 122-131. [CrossRef]

11. Lassus, J.; Gayat, E.; Mueller, C.; Peacock, W.F.; Spinar, J.; Harjola, V.P.; van Kimmenade, R.; Pathak, A.; Mueller, T.; Disomma, S.; et al. Incremental value of biomarkers to clinical variables for mortality prediction in acutely decompensated heart failure: The Multinational Observational Cohort on Acute Heart Failure (MOCA) study. Int. J. Cardiol. 2013, 168, 2186-2194. [CrossRef] [PubMed]

12. Kohli, P.; Bonaca, M.P.; Kakkar, R.; Kudinova, A.Y.; Scirica, B.M.; Sabatine, M.S.; Murphy, S.A.; Braunwald, E.; Lee, R.T.; Morrow, D.A. Role of ST2 in non-ST-elevation acute coronary syndrome in the MERLIN-TIMI 36 trial. Clin. Chem. 2012, 58, 257-266. [CrossRef] [PubMed]

13. Anand, I.S.; Rector, T.S.; Kuskowski, M.; Snider, J.; Cohn, J.N. Prognostic value of soluble ST2 in the Valsartan Heart Failure Trial. Circ. Heart Fail. 2014, 7, 418-426. [CrossRef] [PubMed]

14. Dieplinger, B.; Januzzi, J.L., Jr.; Steinmair, M.; Gabriel, C.; Poelz, W.; Haltmayer, M.; Mueller, T. Analytical and clinical evaluation of a novel high-sensitivity assay for measurement of soluble ST2 in human plasma-The presage ST2 assay. Clin. Chim. Acta 2009, 409, 33-40. [CrossRef] [PubMed]

15. Ho, J.E.; Lyass, A.; Courchesne, P.; Chen, G.; Liu, C.; Yin, X.; Hwang, S.J.; Massaro, J.M.; Larson, M.G.; Levy, D. Protein biomarkers of cardiovascular disease and mortality in the community. J. Am. Heart Assoc. 2018, 7. [CrossRef] [PubMed]

16. Kazimierczyk, E.; Kazimierczyk, R.; Harasim-Symbor, E.; Kaminski, K.; Sobkowicz, B.; Chabowski, A.; Tycinska, A. Persistently elevated plasma heart-type fatty acid binding protein concentration is related with poor outcome in acute decompensated heart failure patients. Clin. Chim. Acta 2018, 487, 48-53. [CrossRef] [PubMed]

17. Koller, L.; Stojkovic, S.; Richter, B.; Sulzgruber, P.; Potolidis, C.; Liebhart, F.; Mortl, D.; Berger, R.; Goliasch, G.; Wojta, J.; et al. Soluble urokinase-type plasminogen activator receptor improves risk prediction in patients with chronic heart failure. JACC Heart Fail. 2017, 5, 268-277. [CrossRef]

18. Li, J.; Cui, Y.; Huang, A.; Li, Q.; Jia, W.; Liu, K.; Qi, X. Additional diagnostic value of growth differentiation factor-15 (GDF-15) to N-Terminal B-type natriuretic peptide (NT-proBNP) in patients with different stages of heart failure. Med. Sci. Monit. 2018, 24, 4992-4999. [CrossRef]

19. Vorovich, E.; French, B.; Ky, B.; Goldberg, L.; Fang, J.C.; Sweitzer, N.K.; Cappola, T.P. Biomarker predictors of cardiac hospitalization in chronic heart failure: A recurrent event analysis. J. Card. Fail. 2014, 20, 569-576. [CrossRef]

20. Weinberg, E.O.; Shimpo, M.; Hurwitz, S.; Tominaga, S.; Rouleau, J.L.; Lee, R.T. Identification of serum soluble ST2 receptor as a novel heart failure biomarker. Circulation 2003, 107, 721-726. [CrossRef]

21. Lang, R.M.; Badano, L.P.; Mor-Avi, V.; Afilalo, J.; Armstrong, A.; Ernande, L.; Flachskampf, F.A.; Foster, E.; Goldstein, S.A.; Kuznetsova, T.; et al. Recommendations for cardiac chamber quantification by echocardiography in adults: An update from the American Society of Echocardiography and the European Association of Cardiovascular Imaging. Eur. Heart J. Cardiovasc. Imaging. 2015, 16, 233-270. [CrossRef] [PubMed]

22. Viswanathan, K.; Hall, A.S.; Barth, J.H. An evidence-based approach to the assessment of heart-type Fatty Acid binding protein in acute coronary syndrome. Clin. Biochem. Rev. 2012, 33, 3-11. [PubMed] 
23. Lippi, G.; Schena, F.; Montagnana, M.; Salvagno, G.L.; Guidi, G.C. Influence of acute physical exercise on emerging muscular biomarkers. Clin. Chem. Lab. Med. 2008, 46, 1313-1318. [CrossRef] [PubMed]

24. Sponder, M.; Lichtenauer, M.; Wernly, B.; Paar, V.; Hoppe, U.; Emich, M.; Fritzer-Szekeres, M.; Litschauer, B.; Strametz-Juranek, J. Serum heart-type fatty acid-binding protein decreases and soluble isoform of suppression of tumorigenicity 2 increases significantly by long-term physical activity. J. Investig. Med. 2018. [CrossRef] [PubMed]

25. Shirazi, L.F.; Bissett, J.; Romeo, F.; Mehta, J.L. Role of inflammation in heart failure. Curr. Atheroscler. Rep. 2017, 19, 27. [CrossRef] [PubMed]

26. Rasmussen, L.J.; Ladelund, S.; Haupt, T.H.; Ellekilde, G.; Poulsen, J.H.; Iversen, K.; Eugen-Olsen, J.; Andersen, O. Soluble urokinase plasminogen activator receptor (suPAR) in acute care: A strong marker of disease presence and severity, readmission and mortality. A retrospective cohort study. Emerg. Med. J. 2016, 33, 769-775. [CrossRef] [PubMed]

27. Yang, H.; Filipovic, Z.; Brown, D.; Breit, S.N.; Vassilev, L.T. Macrophage inhibitory cytokine-1: A novel biomarker for p53 pathway activation. Mol. Cancer Ther. 2003, 2, 1023-1029.

28. Vousden, K.H.; Lane, D.P. p53 in health and disease. Nat. Rev. Mol. Cell Biol. 2007, 8, 275-283. [CrossRef]

29. Li, J.; Yang, L.; Qin, W.; Zhang, G.; Yuan, J.; Wang, F. Adaptive induction of growth differentiation factor 15 attenuates endothelial cell apoptosis in response to high glucose stimulus. PLoS ONE 2013, 8, e65549. [CrossRef]

30. Schillaci, G.; Verdecchia, P.; Porcellati, C.; Cuccurullo, O.; Cosco, C.; Perticone, F. Continuous relation between left ventricular mass and cardiovascular risk in essential hypertension. Hypertension 2000, 35, 580-586. [CrossRef]

31. Xu, X.Y.; Nie, Y.; Wang, F.F.; Bai, Y.; Lv, Z.Z.; Zhang, Y.Y.; Li, Z.J.; Gao, W. Growth differentiation factor (GDF)-15 blocks norepinephrine-induced myocardial hypertrophy via a novel pathway involving inhibition of epidermal growth factor receptor transactivation. J. Biol. Chem. 2014, 289, 10084-10094. [CrossRef] [PubMed]

32. Ding, Q.; Mracek, T.; Gonzalez-Muniesa, P.; Kos, K.; Wilding, J.; Trayhurn, P.; Bing, C. Identification of macrophage inhibitory cytokine-1 in adipose tissue and its secretion as an adipokine by human adipocytes. Endocrinology 2009, 150, 1688-1696. [CrossRef] [PubMed]

33. Schlittenhardt, D.; Schober, A.; Strelau, J.; Bonaterra, G.A.; Schmiedt, W.; Unsicker, K.; Metz, J.; Kinscherf, R. Involvement of growth differentiation factor-15/macrophage inhibitory cytokine-1 (GDF-15/MIC-1) in oxLDL-induced apoptosis of human macrophages in vitro and in arteriosclerotic lesions. Cell Tissue Res. 2004, 318, 325-333. [CrossRef] [PubMed]

34. Lok, S.I.; Winkens, B.; Goldschmeding, R.; van Geffen, A.J.; Nous, F.M.; van Kuik, J.; van der Weide, P.; Klopping, C.; Kirkels, J.H.; Lahpor, J.R.; et al. Circulating growth differentiation factor- 15 correlates with myocardial fibrosis in patients with non-ischaemic dilated cardiomyopathy and decreases rapidly after left ventricular assist device support. Eur. J. Heart Fail. 2012, 14, 1249-1256. [CrossRef] [PubMed]

35. Kempf, T.; Sinning, J.M.; Quint, A.; Bickel, C.; Sinning, C.; Wild, P.S.; Schnabel, R.; Lubos, E.; Rupprecht, H.J.; Munzel, T.; et al. Growth-differentiation factor-15 for risk stratification in patients with stable and unstable coronary heart disease: Results from the AtheroGene study. Circ. Cardiovasc. Genet. 2009, 2, $286-292$. [CrossRef] [PubMed]

36. Schopfer, D.W.; Ku, I.A.; Regan, M.; Whooley, M.A. Growth differentiation factor 15 and cardiovascular events in patients with stable ischemic heart disease (The Heart and Soul Study). Am. Heart J. 2014, 167, 186-192. [CrossRef]

37. Bonaca, M.P.; Morrow, D.A.; Braunwald, E.; Cannon, C.P.; Jiang, S.; Breher, S.; Sabatine, M.S.; Kempf, T.; Wallentin, L.; Wollert, K.C. Growth differentiation factor-15 and risk of recurrent events in patients stabilized after acute coronary syndrome: Observations from PROVE IT-TIMI 22. Arterioscler. Thromb. Vasc. Biol. 2011, 31, 203-210. [CrossRef] [PubMed]

38. Eggers, K.M.; Kempf, T.; Lagerqvist, B.; Lindahl, B.; Olofsson, S.; Jantzen, F.; Peter, T.; Allhoff, T.; Siegbahn, A.; Venge, P.; et al. Growth-differentiation factor-15 for long-term risk prediction in patients stabilized after an episode of non-ST-segment-elevation acute coronary syndrome. Circ. Cardiovasc. Genet. 2010, 3, 88-96. [CrossRef] 
39. Anand, I.S.; Kempf, T.; Rector, T.S.; Tapken, H.; Allhoff, T.; Jantzen, F.; Kuskowski, M.; Cohn, J.N.; Drexler, H.; Wollert, K.C. Serial measurement of growth-differentiation factor-15 in heart failure: Relation to disease severity and prognosis in the Valsartan Heart Failure Trial. Circulation 2010, 122, 1387-1395. [CrossRef]

40. Chan, M.M.; Santhanakrishnan, R.; Chong, J.P.; Chen, Z.; Tai, B.C.; Liew, O.W.; Ng, T.P.; Ling, L.H.; Sim, D.; Leong, K.T.; et al. Growth differentiation factor 15 in heart failure with preserved vs. reduced ejection fraction. Eur. J. Heart Fail. 2016, 18, 81-88. [CrossRef]

41. Paulus, W.J.; Tschope, C. A novel paradigm for heart failure with preserved ejection fraction: Comorbidities drive myocardial dysfunction and remodeling through coronary microvascular endothelial inflammation. J. Am. Coll. Cardiol. 2013, 62, 263-271. [CrossRef] [PubMed]

42. Ahmad, T.; Wang, T.; O’Brien, E.C.; Samsky, M.D.; Pura, J.A.; Lokhnygina, Y.; Rogers, J.G.; Hernandez, A.F.; Craig, D.; Bowles, D.E.; et al. Effects of left ventricular assist device support on biomarkers of cardiovascular stress, fibrosis, fluid homeostasis, inflammation, and renal injury. JACC Heart Fail. 2015, 3, 30-39. [CrossRef] [PubMed]

43. Wang, Y.; Jiang, T.; Jiang, M.; Gu, S. Appraising growth differentiation factor 15 as a promising biomarker in digestive system tumors: A meta-analysis. BMC Cancer 2019, 19, 177. [CrossRef] [PubMed]

44. Hsu, L.A.; Wu, S.; Juang, J.J.; Chiang, F.T.; Teng, M.S.; Lin, J.F.; Huang, H.L.; Ko, Y.L. Growth differentiation factor 15 may predict mortality of peripheral and coronary artery diseases and correlate with their risk factors. Mediators Inflamm. 2017, 2017, 9398401. [CrossRef] [PubMed]

(C) 2019 by the authors. Licensee MDPI, Basel, Switzerland. This article is an open access article distributed under the terms and conditions of the Creative Commons Attribution (CC BY) license (http://creativecommons.org/licenses/by/4.0/). 